\title{
Combined aliskiren and L-arginine treatment has antihypertensive effects and prevents vascular endothelial dysfunction in a model of renovascular hypertension
}

\author{
C.H. Santuzzi, R.V. Tiradentes, V. Mengal, E.R.G. Claudio, H. Mauad, S.A. Gouvea and G.R. Abreu \\ Departamento de Ciências Fisiológicas, Centro de Ciências da Saúde, Universidade Federal do Espírito Santo, Vitória, ES, Brasil
}

\begin{abstract}
Angiotensin II is a key player in the pathogenesis of renovascular hypertension, a condition associated with endothelial dysfunction. We investigated aliskiren (ALSK) and L-arginine treatment both alone and in combination on blood pressure (BP), and vascular reactivity in aortic rings. Hypertension was induced in 40 male Wistar rats by clipping the left renal artery. Animals were divided into Sham, 2-kidney, 1-clip (2K1C) hypertension, 2K1C+ALSK (ALSK), 2K1C+L-arginine (L-arg), and $2 \mathrm{~K} 1 \mathrm{C}+\mathrm{ALSK}+\mathrm{L}$-arginine (ALSK + L-arg) treatment groups. For 4 weeks, BP was monitored and endothelium-dependent and independent vasoconstriction and relaxation were assessed in aortic rings. ALSK $+\mathrm{L}$-arg reduced BP and the contractile response to phenylephrine and improved acetylcholine relaxation. Endothelium removal and incubation with $\mathrm{N}$-nitro-L-arginine methyl ester (L-NAME) increased the response to phenylephrine in all groups, but the effect was greater in the ALSK $+\mathrm{L}-\mathrm{arg}$ group. Losartan reduced the contractile response in all groups, apocynin reduced the contractile response in the 2K1C, ALSK and ALSK + L-arg groups, and incubation with superoxide dismutase reduced the phenylephrine response in the $2 \mathrm{~K} 1 \mathrm{C}$ and ALSK groups. eNOS expression increased in the $2 \mathrm{~K} 1 \mathrm{C}$ and L-arg groups, and iNOS was increased significantly only in the $2 \mathrm{~K} 1 \mathrm{C}$ group compared with other groups. AT 1 expression increased in the $2 \mathrm{~K} 1 \mathrm{C}$ compared with the Sham, ALSK and ALSK $+\mathrm{L}$-arg groups, $\mathrm{AT}_{2}$ expression increased in the ALSK $+\mathrm{L}$-arg group compared with the Sham and $\mathrm{L}$-arg groups, and gp91phox decreased in the ALSK + L-arg group compared with the 2K1C and ALSK groups. In conclusion, combined $\mathrm{ALSK}+\mathrm{L}$-arg was effective in reducing $\mathrm{BP}$ and preventing endothelial dysfunction in aortic rings of $2 \mathrm{~K} 1 \mathrm{C}$ hypertensive rats. The responsible mechanisms appear to be related to the modulation of the local renin-angiotensin system, which is associated with a reduction in endothelial oxidative stress.
\end{abstract}

Key words: 2K1C hypertension; endothelial dysfunction; aliskiren; L-arginine; RAAS and oxidative stress

\section{Introduction}

Hypertension is manifested not only by increased arterial pressure but also by complex structural and functional alterations of its target organs. Long-term hypertension often results in left ventricular hypertrophy, which is considered a risk factor for coronary heart disease (1), and also causes structural alterations of the vascular wall characterized by endothelial dysfunction, extracellular matrix deposition, medial layer thickening due to hypertrophy/hyperplasia, and migration of vascular smooth muscle cells (VSMCs) (2). Chronic kidney artery diseases, such as renal artery stenosis, generally lead to hypertension, and a kidney-related animal model of hypertension, the 2-kidney, 1-clip (2K1C) model, is produced by subjecting a renal artery to partial stenosis by clip placement. Kidney ischemia results in an increase of plasma renin activity and the consequent increase in angiotensinogen concentration leads to a persistent rise in blood pressure $(2,3)$. This hypertension model is associated with increased angiotensin II levels, and this peptide produces mitogenic effects, which are critically involved in the development of the structural and functional vascular changes caused by hypertension (4). In experimental $2 \mathrm{~K} 1 \mathrm{C}$ hypertension, the overproduction of reactive oxygen species (ROS), which leads to oxidative stress, plays an important role in the pathogenesis of renovascular hypertension and enhanced oxidation-sensitive signaling pathway activation (5). Previous studies have reported that angiotensin II stimulates the production of ROS such as superoxide through the activation of membrane-bound nicotinamide adenine dinucleotide 
(NADH) or nicotinamide adenine dinucleotide phosphate (NADPH) oxidase (6).

Endothelial dysfunction has an important role in the pathogenesis and progression of hypertensive heart disease (7). Increased oxidative stress impairs endothelial function and is one of the primary mediators of the development of hypertension, atherosclerosis, diabetes, cardiac hypertrophy, heart failure, ischemia-reperfusion injury, and stroke (8).

Drugs that target the renin-angiotensin-aldosterone system (RAAS), such as angiotensin-converting enzyme (ACE) inhibitors and blockers of angiotensin receptor-1 $\left(A T_{1}\right)$, are effective in reducing blood pressure and morbidity and mortality. Their low rate of side effects makes them well tolerated and therefore attractive as firstline agents for the treatment of arterial hypertension (9). Aliskiren (ALSK), a recent addition to the family of RAASblockers, is a direct renin inhibitor indicated for the treatment of hypertension. Several studies have previously investigated the effectiveness of ALSK both as monotherapy and in combination with other agents in lowering blood pressure (10). Some studies have evaluated ALSK administered once a day to reduce blood pressure compared with ramipril (11), losartan (12), irbesartan (13), and hydrochlorothiazide (14). In those studies, which included patients with mild-to-moderate essential hypertension, ALSK led to a decrease in blood pressure similar to the other agents or drugs. However, whether ALSK reduces persistent hypertension, such as that produced in 2K1C models, has not been demonstrated.

Our previous results demonstrated that treatment with L-arginine, a substrate for nitric oxide (NO) production, reduces blood pressure in the $2 \mathrm{~K} 1 \mathrm{C}$ hypertension model, not only because of its known effects on NO formation and vasodilation but also because of increased renal excretion of water and sodium (15). Recently, L-arginine supplementation in patients with mild arterial hypertension was shown to stimulate NO biosynthesis and reduce oxidative stress (16). Gokce (17) reported that the Larginine-mediated mechanisms of reduction in arterial hypertension include improvement of vasomotor functions of the endothelium, increased synthesis of NO in vessels, decreased activity of endothelin-1 and angiotensin II, modulation of hemodynamic changes in kidneys, lowering of oxidative stress, and improved insulin sensitivity.

This study investigated the effects of ALSK, L-arginine and the combination of ALSK and L-arginine on blood pressure and vascular reactivity in aortic rings in a renovascular $2 \mathrm{~K} 1 \mathrm{C}$ hypertension model, with a focus on the renin-angiotensin system and the involvement of oxidative stress in renovascular hypertension-induced endothelial dysfunction.

\section{Material and Methods}

Animals and treatment

Male Wistar rats (150-170 g, $\mathrm{n}=8$ per group) were used in these experimental procedures. The care and use of laboratory animals were in accordance with the $\mathrm{NIH}$ guidelines. All experiments were conducted in compliance with the Guidelines for Biomedical Research as stated by the Brazilian Societies of Experimental Biology and were approved by the Institutional Ethics Committee of the Universidade Federal do Espírito Santo (CEUA-UFES 004/2010). All rats had free access to water and were fed rat chow ad libitum. Rats were divided into five groups: Sham (normotensive control, $0.1 \mathrm{~mL}$ saline vehicle by gavage); 2K1C (hypertension control, untreated); 2K1C treated with ALSK $(50 \mathrm{mg} / \mathrm{kg}, 0.3 \mathrm{~mL} /$ day by gavage); $2 \mathrm{~K} 1 \mathrm{C}$ treated with L-arginine $(10 \mathrm{mg} / \mathrm{kg}, 0.1 \mathrm{~mL} /$ day L-arg by gavage), and $2 \mathrm{~K} 1 \mathrm{C}$ treated with $\mathrm{ALSK}+\mathrm{L}$-arginine (50 mg/kg ALSK, $0.3 \mathrm{~mL} /$ day $+10 \mathrm{mg} / \mathrm{kg} \mathrm{L-arg,} 0.1 \mathrm{~mL}$ ) day, both by gavage). At the end of treatment, rats were anesthetized by intraperioneal (ip) injection of pentobarbital $(35 \mathrm{mg} / \mathrm{kg})$ and killed by exsanguination. The thoracic aorta was carefully dissected and connective tissue removed. For vascular reactivity experiments, the aortas were divided into cylindrical segments $4 \mathrm{~mm}$ in length. For analysis of protein expression, some arteries were rapidly frozen in liquid nitrogen and stored at $-80^{\circ} \mathrm{C}$ until analyzed.

\section{Renovascular hypertensive model}

Renovascular hypertension was induced by the Goldblatt 2K1C method as described in our previous reports $(15,18)$. To minimize stress-induced fluctuation of systolic blood pressure (SBP), rats were trained by measuring SBP daily for at least 7 days before the $2 \mathrm{~K} 1 \mathrm{C}$ procedure or the sham operation. Then, a retroperitoneal flank incision was performed in the rats anesthetized with sodium pentobarbital (35 mg/kg, ip). The left renal artery was exposed via midline laparotomy. Renovascular hypertension was induced by partial occlusion of the artery by a U-shaped silver clip with an internal diameter of $0.20 \mathrm{~mm}$. Sham rats (normotensive sham operated) underwent a similar surgical procedure but without clip placement. The criterion for hypertension in the present study was an SBP $>160 \mathrm{mmHg}$, and only hypertensive $2 \mathrm{~K} 1 \mathrm{C}$ rats with $\mathrm{SBP}>160 \mathrm{mmHg}$ were used in the experimental procedures.

\section{Blood pressure measurements}

Indirect SBP was measured by tail-cuff plethysmography (IITC Life Science, Inc., USA). Conscious rats were restrained for 5-10 min in a warm, quiet room and conditioned to numerous cuff inflation-deflation cycles by a trained operator. SBP was measured before surgery (time 0) and a week after surgery to confirm that the procedure had been successful and resulted in hypertensive animals (time 7), and at the end of the treatment, 28 days after surgery (time 28). Blood pressure was measured 3 times on all 3 days and the mean of the 3 measurements was recorded for each time. 
Vascular reactivity measurements

Aortic segments $4 \mathrm{~mm}$ in length were mounted between two parallel wires in a $37^{\circ} \mathrm{C}$ organ bath containing Krebs-Henseleit solution (KHS; $124 \mathrm{mM} \mathrm{NaCl}$, $4.6 \mathrm{mM} \mathrm{KCl}, 2.5 \mathrm{mM} \mathrm{CaCl}_{2}, 1.2 \mathrm{mM} \mathrm{MgSO}_{4}, 1.2 \mathrm{mM}$ $\mathrm{KH}_{2} \mathrm{PO}_{4}, 0.01 \mathrm{mM}$ EDTA, $23 \mathrm{mM} \mathrm{NaHCO}, 11 \mathrm{mM}$ glucose) and gassed with $95 \% \quad \mathrm{O}_{2}-5 \% \quad \mathrm{CO}_{2}, \mathrm{pH} 7.4$. Arterial segments were stretched to an optimal resting tension of $1.0 \mathrm{~g}$. Isometric tension was recorded using a force displacement transducer (TSD125C, Biopac Systems, USA) connected to an acquisition system (MP100A, Biopac Systems).

After a 45-min equilibration period, all aortic rings were exposed twice to $75 \mathrm{mM} \mathrm{KCl}$. The first exposure was to determine their functional integrity, and the second exposure was to assess the maximal tension that they could be exposed to. Next, the endothelial integrity was tested with acetylcholine (ACh, $10 \mu \mathrm{M})$ in segments previously contracted with phenylephrine $(1 \mu \mathrm{M})$. After a 45-min washout period, concentration-response curves to phenylephrine $\left(10^{-10}\right.$ to $\left.3 \times 10^{-4} \mathrm{M}\right)$ were determined. Single curves were obtained for each segment.

In all experimental groups, the influence of the endothelium on the response of aortic segments to phenylephrine was investigated after mechanical removal of the endothelium by rubbing the lumen of the segment with a needle. The absence of endothelium was confirmed by the inability of $10 \mu \mathrm{M}$ ACh to produce relaxation.

The role of endothelial-derived vasoactive factors on the phenylephrine-elicited contractile response was investigated. The effects of the following drugs were evaluated: 1) the nonspecific nitric oxide synthase (NOS) inhibitor $\mathrm{N}$-nitro-L-arginine methyl ester (L-NAME, $100 \mu \mathrm{M})$, 2) an $\mathrm{AT}_{1}$ antagonist (losartan, $\left.10 \mu \mathrm{M}\right), 3$ ), an NADPH oxidase inhibitor (apocynin, $0.3 \mathrm{mM}$ ), and 4) superoxide dismutase (SOD) $(150 \mathrm{U} / \mathrm{mL})$. These drugs were added to the bath $30 \mathrm{~min}$ before generating the phenylephrine concentration-response curves.

In another set of experiments conducted after the 45-min equilibration period, the aortic rings from all of the experimental groups were precontracted with phenylephrine $(1 \mu \mathrm{M})$ until they reached a plateau (approximately $15 \mathrm{~min})$, and concentration-response curves to ACh $\left(10^{-10}\right.$ to $\left.3 \times 10^{-4} \mathrm{M}\right)$ or sodium nitroprusside (SNP: $10^{-10}$ to $3 \times 10^{-4} \mathrm{M}$ ) were determined.

\section{Western blot analysis}

Aortas were homogenized in lysis buffer containing $150 \mathrm{mM} \mathrm{NaCl}, 50 \mathrm{mM}$ Tris-HCl, $5 \mathrm{mM}$ EDTA.2Na, $1 \mathrm{mM}$ $\mathrm{MgCl}_{2}$ plus protease inhibitor (Sigma Fast; Sigma, USA). The protein concentration was determined by the Lowry method (19), and bovine serum albumin (BSA) was used as a standard. Equal amounts of protein $(50 \mu \mathrm{g})$ were separated by $10 \%$ sodium dodecyl sulfate-polyacrylamide gel electrophoresis (SDS-PAGE). Proteins were transferred to polyvinylidene difluoride (PVDF) membranes that were incubated with mouse monoclonal antibodies against endothelial nitric oxide synthase (eNOS, 1:1500; BD, USA), inducible nitric oxide synthase (iNOS, 1:1500; BD), gp91phox (1:1000; BD) and rabbit polyclonal antibodies for $\mathrm{AT}_{1}$ (1:500; Santa Cruz Biotechnology, USA) and $A_{2}$ (1:1000; Millipore, USA). After washing, the membranes were incubated with alkaline phosphatase conjugated anti-mouse IgG (1:3000, Abcam Inc., USA) or anti-rabbit (1:7000; Santa Cruz Biotechnology) antibodies. The protein bands were visualized using a nitro-blue tetrazolium/5-bromo-4-chloro-3'-indolyphosphate (NBT/ $\mathrm{BCIP}$ ) staining system (Invitrogen Corporation, USA) and quantified using the Image $J$ software (National Institutes of Health, USA). The same membranes were used to assay $\beta$-actin expression using a mouse monoclonal antibody to $\beta$-actin (1:5000; Sigma Chemical, Co., USA), and the results are reported as the ratio of the densities of specific bands to the corresponding $\beta$-actin.

\section{Drugs and reagents}

Rasilez $^{\mathbb{R}}$ (Aliskiren; Novartis, Italy), I-phenylephrine hydrochloride, L-NAME, apocynin, SOD, acetylcholine chloride, sodium pentobarbital, losartan, superoxide dismutase, sodium nitroprusside and L-arginine monohydrochloride were purchased from Sigma-Aldrich (USA). The salts and reagents used were of analytical grade and purchased from Sigma-Aldrich and Merck (Germany).

\section{Statistical analyses}

Data are reported as means \pm SE. Contractile responses are reported as a percentage of the maximal response induced by $75 \mathrm{mM} \mathrm{KCl}$. Relaxation responses to ACh or SNP are reported as the percentage of relaxation of the previous contraction. For each concentration-response curve, the maximal effect $\left(R_{\max }\right)$ and the concentration of agonist that produced $50 \%$ of the maximal response (log $E_{50}$ ) were calculated using nonlinear regression analysis. The sensitivities of the agonists are reported as $\mathrm{pD}_{2}\left(-\log \mathrm{EC}_{50}\right)$.

To compare the effects of endothelium denudation, L-NAME, losartan, and apocynin on the contractile responses to phenylephrine, some of the results are reported as differences in the area under the concentration-response curve (dAUC) for the control $(E+)$ and each experimental group (E-, L-NAME, losartan, SOD and apocynin). These data indicated whether the size of the effect of endothelial denudation, L-NAME, losartan, SOD, and apocynin was significantly different in shamtreated segments and segments in the $2 \mathrm{~K} 1 \mathrm{C}, \mathrm{ALSK}, \mathrm{L}$-arg and $\mathrm{ALSK}+\mathrm{L}$-arg groups. The means were compared using one-way and two-way ANOVA, followed by Tukey's post hoc test when appropriate.

For protein expression, data are reported as the ratio of the immunoblot densities corresponding to the protein of interest and $\beta$-actin. The means were analyzed using one-way ANOVA followed by Fisher's post hoc test. For 

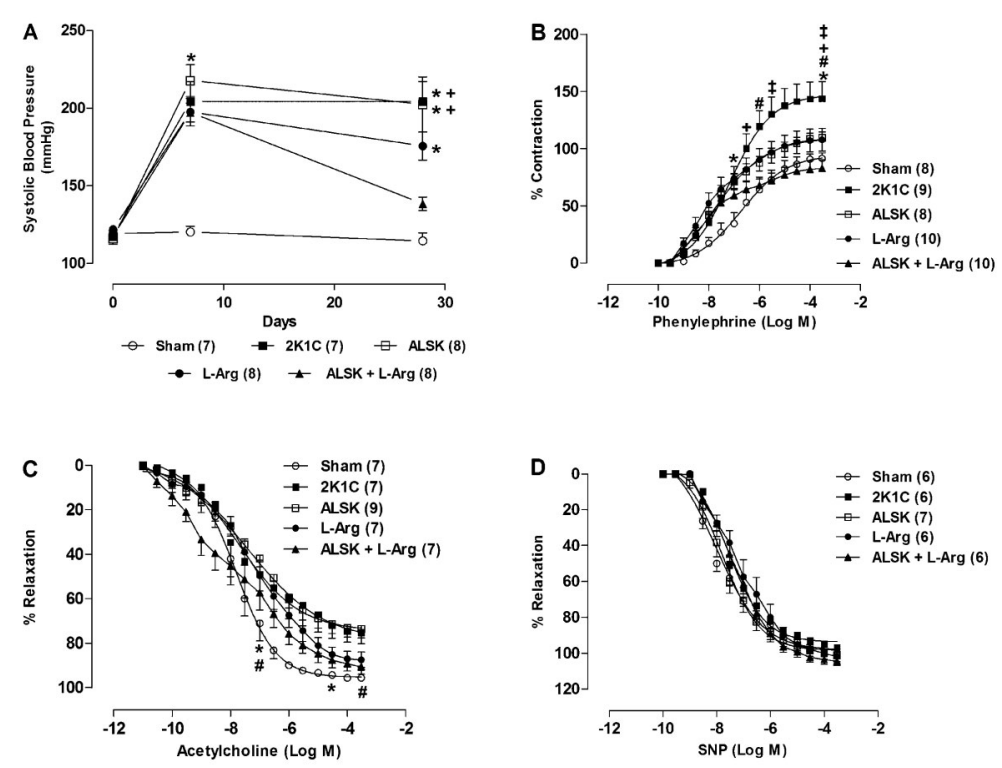

Figure 1. Effects of aliskiren (ALSK), L-arginine (L-arg) and a combination of both on systolic blood pressure throughout the experiment $(A)$. Effects of ALSK and L-arg treatment in renovascular hypertension on the concentration-response curves to phenylephrine $(B)$, acetylcholine $(C)$ and sodium nitroprusside (SNP) $(D)$ in the aortic rings. Data are reported as means $\pm \mathrm{SE}$. The number of animals in each group is indicated in parentheses. ${ }^{*} \mathrm{P}<0.05$ vs Sham; ${ }^{*} \mathrm{P}<0.05$ vs ALSK; ${ }^{\mathrm{P}}<0.05$ vs L-arg; ${ }^{+} \mathrm{P}<0.05$ vs ALSK +L-arg (two-way ANOVA, followed by Tukey's post hoc test). all analyses, the differences were considered significant at $\mathrm{P}<0.05$.

\section{Results}

\section{Effect of ALSK and L-arginine treatment on SBP}

The baseline SBP (time 0) was similar in the 5 experimental groups before surgery (Sham: 112.2 \pm
$1.01 \mathrm{mmHg}, \mathrm{n}=7 ; 2 \mathrm{~K} 1 \mathrm{C}: 120.4 \pm 2.11 \mathrm{mmHg}, \mathrm{n}=7$; ALSK: $124.6 \pm 1.20 \mathrm{mmHg}, \mathrm{n}=8$; L-arg: $115.6 \pm$ $3.3 \mathrm{mmHg}, \mathrm{n}=8$, and ALSK $+\mathrm{L}$-arg: $118.8 \pm$ $2.70 \mathrm{mmHg}, \mathrm{n}=8$ ), and no significant change in SBP was seen in the Sham group at the end of treatment $(114.4 \pm 5.2 \mathrm{mmHg}, \mathrm{n}=7)$. Surgical renal stenosis was associated with a significant increase in SBP compared with the sham operation, and was detectable as early as 7

Table 1. Parameters of maximal response $\left(R_{\max }\right)$ and sensitivity $\left(\mathrm{pD}_{2}\right)$ of the concentration-response curves to phenylephrine in the aortas from all experimental groups, before $(E+)$ and after endothelial denudation $(E-)$ and after incubation with L-NAME $(100 \mu M)$, losartan $(10 \mu \mathrm{M})$, apocynin $(0.3 \mathrm{nM})$ and SOD $(150 \mathrm{U} / \mathrm{mL})$.

\begin{tabular}{|c|c|c|c|c|c|c|}
\hline & Control $(E+)$ & E- & L-NAME & Losartan & Apocynin & SOD \\
\hline \multicolumn{7}{|l|}{ Sham } \\
\hline $\mathrm{R}_{\max }$ & $92.4 \pm 4.4^{\S}$ & $130.3 \pm 3.66^{\perp}$ & $133.5 \pm 10.6^{\perp}$ & $93.3 \pm 6.8$ & $91.7 \pm 3.6$ & $87.4 \pm 6.8$ \\
\hline $\mathrm{pD}_{2}$ & $6.77 \pm 0.35$ & $7.93 \pm 0.20^{\perp}$ & $8.45 \pm 0.30^{\perp}$ & $7.55 \pm 0.28$ & $7.83 \pm 0.21$ & $7.3 \pm 0.21$ \\
\hline \multicolumn{7}{|l|}{$2 \mathrm{~K} 1 \mathrm{C}$} \\
\hline $\mathrm{R}_{\max }$ & $148.1 \pm 15.6$ & $166.4 \pm 7.59$ & $163.1 \pm 8.7$ & $86.9 \pm 8.6^{\perp}$ & $42.7 \pm 4.32^{* \perp}$ & $62.9 \pm 7.1^{\perp}$ \\
\hline $\mathrm{pD}_{2}$ & $7.25 \pm 0.14$ & $8.90 \pm 0.32^{\perp}$ & $7.94 \pm 0.12^{\perp}$ & $7.93 \pm 0.32$ & $7.70 \pm 0.17$ & $7.8 \pm 0.25^{\perp}$ \\
\hline \multicolumn{7}{|l|}{ ALSK } \\
\hline $\mathrm{R}_{\max }$ & $112.3 \pm 7.4$ & $136.7 \pm 12.9$ & $218.5 \pm 40.7^{\perp}$ & $78.8 \pm 6.4^{\perp}$ & $60.7 \pm 16.8^{\perp}$ & $72.9 \pm 8.3^{\perp}$ \\
\hline $\mathrm{pD}_{2}$ & $7.74 \pm 0.21$ & $8.23 \pm 0.20$ & $7.84 \pm 0.28$ & $8.47 \pm 0.15$ & $10.2 \pm 1.85$ & $7.7 \pm 0.31$ \\
\hline \multicolumn{7}{|l|}{ L-arg } \\
\hline $\mathrm{R}_{\max }$ & $106.6 \pm 8.8^{\S}$ & $161.8 \pm 10.5^{\perp}$ & $158.1 \pm 9.1^{\perp}$ & $44.7 \pm 9.0^{\star \S \perp}$ & $85.2 \pm 17.1$ & $72.2 \pm 14.1$ \\
\hline $\mathrm{pD}_{2}$ & $8.20 \pm 0.24^{*}$ & $8.60 \pm 0.20$ & $8.06 \pm 0.26$ & $10.9 \pm 2.87$ & $14.4 \pm 3.05$ & $8.3 \pm 0.34$ \\
\hline \multicolumn{7}{|c|}{ ALSK + L-arg } \\
\hline $\mathrm{R}_{\max }$ & $84.39 \pm 7.6^{\S}$ & $162.4 \pm 13.9^{\perp}$ & $187.8 \pm 19.1^{\perp}$ & $52.8 \pm 6.3^{\S * \perp}$ & $35.7 \pm 5.0^{* \star \perp}$ & $67.3 \pm 4.7$ \\
\hline $\mathrm{pD}_{2}$ & $8.28 \pm 0.37^{\S}$ & $8.13 \pm 0.43$ & $8.37 \pm 0.15$ & $7.7 \pm 0.33$ & $10.5 \pm 1.60$ & $8.5 \pm 0.54$ \\
\hline
\end{tabular}

Data are reported as means $\pm S E$. $R_{\text {max }}$ maximal effect (reported as a percentage of the maximal response induced by $75 \mathrm{mM} \mathrm{KCl);}$ pD2: -log one-half $R_{\max }$; E-: endothelium removal; L-NAME: $N^{G}$-nitro-L-arginine methyl ester; SOD: superoxide dismutase. ${ }^{*} P<0.05$ vs Sham; ${ }^{\S} \mathrm{P}<0.05$ vs $2 \mathrm{~K} 1 \mathrm{C}$; ${ }^{\circledR} \mathrm{P}<0.05$ vs $\mathrm{L}$-arg; and ${ }^{\perp} \mathrm{P}<0.05$ vs control $\mathrm{E}+$ (two-way ANOVA, followed by Tukey's post hoc test). 

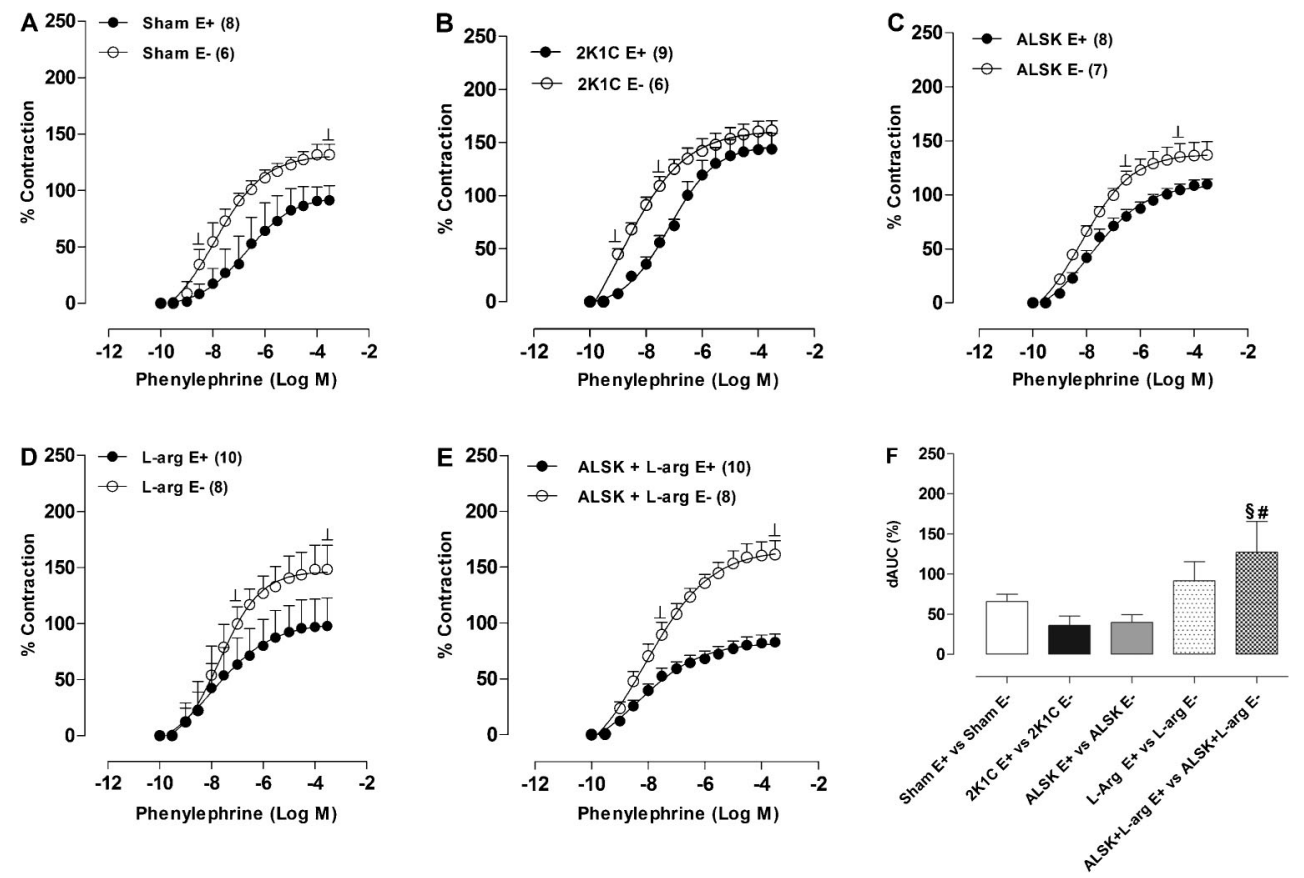

Figure 2. Effects of endothelium removal (E-) on the concentration-response curve for phenylephrine in the aortic rings from Sham $(A)$, 2K1C $(B)$, aliskiren (ALSK) $(C)$, L-arginine $(\mathrm{L}-\arg )(D)$ and $\mathrm{ALSK}+\mathrm{L}-\arg (E)$ treatment in the aortic rings with $(\mathrm{E}+)$ and without $(\mathrm{E}-)$ endothelium. The differences in the area under the concentration-response curves (dAUC) in endothelium-denuded and intact segments is shown in F. Data are reported as means \pm SE. The number of animals in each group is indicated in parentheses. ${ }^{\#} \mathrm{P}<0.05$ vs ALSK; ${ }^{\circledR} \mathrm{P}<0.05$ vs $2 \mathrm{~K} 1 \mathrm{C}$ and ${ }^{\perp} \mathrm{P}<0.05$ vs $\mathrm{E}+$ (two-way ANOVA, followed by Tukey's post hoc test).

days after surgery (2K1C: $204 \pm 12.7 \mathrm{mmHg}, \mathrm{n}=7$; ALSK: $217.8 \pm 10.2 \mathrm{mmHg}, \mathrm{n}=7$; L-arg: $197.5 \pm 8.9 \mathrm{mmHg}$, $\mathrm{n}=8$; ALSK + L-arg: $197.1 \pm 6.08 \mathrm{mmHg}, \mathrm{n}=8$ vs Sham: $119.2 \pm 2.51)$. After 21 days of treatment, only the combined administration of ALSK + L-arg (138.4 \pm $4.37 \mathrm{mmHg}, \mathrm{n}=8$ ) was effective in reducing SBP $(\mathrm{P}<0.05)$ compared to $2 \mathrm{~K} 1 \mathrm{C}(204 \pm 12.7 \mathrm{mmHg}, \mathrm{n}=6)$. Additionally, the ALSK $(202.4 \pm 17.7 \mathrm{mmHg}, \mathrm{n}=7)$ and Larg $(175.6 \pm 9.14 \mathrm{mmHg}, \mathrm{n}=7)$ groups maintained high SBP compared with the Sham group $(114.4 \pm 5.2 \mathrm{mmHg}$, $\mathrm{n}=7$; Figure $1 \mathrm{~A}$ ).

\section{Effects of ALSK and L-arginine treatment on vascular reactivity}

None of the treatments affected the response to $\mathrm{KCl}$ (Sham E + : $2.85 \pm 0.17 \mathrm{~g}, \mathrm{n}=8 ; 2 \mathrm{~K} 1 \mathrm{C} \mathrm{E}+: 2.73 \pm 0.27 \mathrm{~g}$, $\mathrm{n}=9$; ALSK $\mathrm{E}+$ : $2.78 \pm 0.12 \mathrm{~g}, \mathrm{n}=8 ;$ L-arg $\mathrm{E}+$ : $2.40 \pm 0.15 \mathrm{~g}, \mathrm{n}=10 ; A L S K+L-a r g E+: 2.41 \pm 0.13 \mathrm{~g}$, $\mathrm{n}=10$; and Sham E-: $2.88 \pm 0.11 \mathrm{~g}, \mathrm{n}=7 ; 2 \mathrm{~K} 1 \mathrm{C} \mathrm{E}-$ : $2.87 \pm 0.32 \mathrm{~g}, \mathrm{n}=8$; ALSK E-: $2.38 \pm 0.18 \mathrm{~g}, \mathrm{n}=8$; L-arg E-: $2.75 \pm 0.32 \mathrm{~g}, \mathrm{n}=8$; ALSK + L-arg E-: $2.42 \pm 0.21 \mathrm{~g}$, $\mathrm{n}=8 ; \mathrm{P}>0.05$ ). Renovascular hypertension ( $2 \mathrm{~K} 1 \mathrm{C}$ group) increased the contractile responses induced by phenylephrine in rat aortas (Figure 1B). It also increased $R_{\max }$ compared with the Sham, L-arg and ALSK + L-arg groups, but not the sensitivity to phenylephrine (Table 1).
The concentration-dependent relaxation induced by ACh showed impairment at some concentrations in the $2 \mathrm{~K} 1 \mathrm{C}$ and ALSK groups compared with the Sham group (Figure $1 \mathrm{C}$ ), but no differences were seen in $R_{\max }$ and sensitivity to phenylephrine (Table 1). The response induced by SNP did not change in any of the groups (Figure 1D).

\section{Effects of ALSK and L-arginine treatment on the endothelial modulation of vasoconstrictor responses}

To evaluate the influence of endothelium on phenylephrine-induced contraction, we mechanically removed that layer. The reactivity increased, but the responses were smaller in the $2 \mathrm{~K} 1 \mathrm{C}$ group and in the ALSK group (Figure 2). This difference was clearly seen when dAUC was compared (2K1C: $36.3 \pm 11.5$; ALSK: $39.8 \pm 9.5$ vs ALSK + L-arg: $127.3 \pm 38.3, \quad \mathrm{P}<0.05$; Figure $2 \mathrm{~F}$ ). Similarly, $R_{\max }$ was increased in the Sham, L-arg and $A L S K+L-a r g$ groups compared with the control $(E+)$, and the sensitivity to phenylephrine was altered in both the Sham and $2 \mathrm{~K} 1 \mathrm{C}$ groups (Table 1).

L-NAME $(100 \mu \mathrm{M})$ was used to investigate the putative role of $\mathrm{NO}$ in the effects of ALSK and L-arginine treatment on the contractile response induced by phenylephrine. The concentration-response curve for phenylephrine was left-shifted in the aortic segments from all 

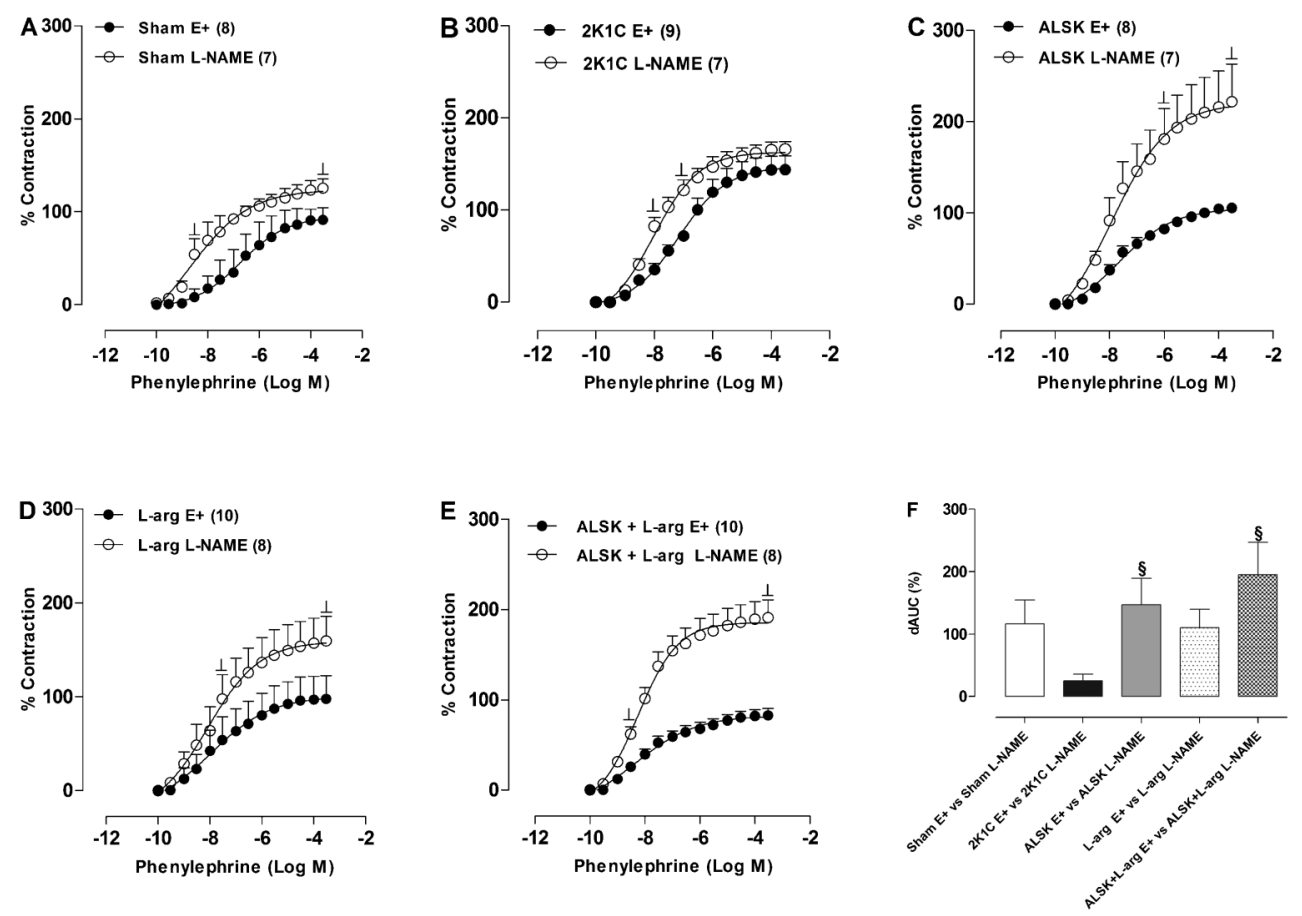

Figure 3. Effects of $N^{G}$-nitro-L-arginine methyl ester blocker (L-NAME, $\left.100 \mu \mathrm{M}\right)$ on the concentration-response curve for phenylephrine in the aortic rings from Sham $(A), 2 \mathrm{~K} 1 \mathrm{C}(B)$, aliskiren (ALSK) $(C)$, L-arginine (L-arg) $(D)$ and $\mathrm{ALSK}+\mathrm{L}$-arg $(E)$ groups in aortic rings in the presence (L-NAME) and absence $(E+)$ of $L-N A M E$ blocker. The differences in the area under the concentration-response curves (dAUC) in the presence and absence of L-NAME is shown in $F$. Data are reported as means $\pm S E$. The number of animals in each group is indicated in parentheses. ${ }^{\S} \mathrm{P}<0.05$ vs $2 \mathrm{~K} 1 \mathrm{C}$ and ${ }^{\perp} \mathrm{P}<0.05$ vs $\mathrm{E}+$ (two-way ANOVA, followed by Tukey's post hoc test).

groups (Figure 3A-E). However, this effect was smaller in the ring preparations from the $2 \mathrm{~K} 1 \mathrm{C}$ group than from the ALSK and ALSK+L-arg treatment groups, as indicated by the dAUC values (2K1C: $25.2 \pm 10.5$ vs ALSK: $147.1 \pm 42.2$ and ALSK+L-arg: $195 \pm 51.7$; Figure 3F). The $R_{\max }$ was increased in the Sham, ALSK, L-arg and ALSK + L-arg groups compared to the controls $(E+)$, and the sensitivity to phenylephrine was increased in the Sham and $2 \mathrm{~K} 1 \mathrm{C}$ groups (Table 1 ).

These results indicated that renovascular hypertension induces endothelial dysfunction in the conductance arteries, thereby reducing endothelial NO modulation of the vasoconstrictor responses. The protein expression of
eNOS (Figure 4A) increased in the $2 \mathrm{~K} 1 \mathrm{C}$ hypertension and L-arg groups; treatment with either ALSK or ALSK + L-arg reduced eNOS protein expression in the aorta (Figure 4A). In addition, the protein expression of iNOS (Figure 4B) increased significantly in the $2 \mathrm{~K} 1 \mathrm{C}$ group compared to the Sham, ALSK, L-arg and ALSK+ L-arg groups (Figure 4B).

\section{Role of the RAAS in the effects of ALSK and L- arginine treatment on the phenylephrine response}

To investigate whether the local RAAS was involved in alterations of the vascular reactivity to phenylephrine induced by $2 \mathrm{~K} 1 \mathrm{C}$ and the effects of ALSK and L-arginine
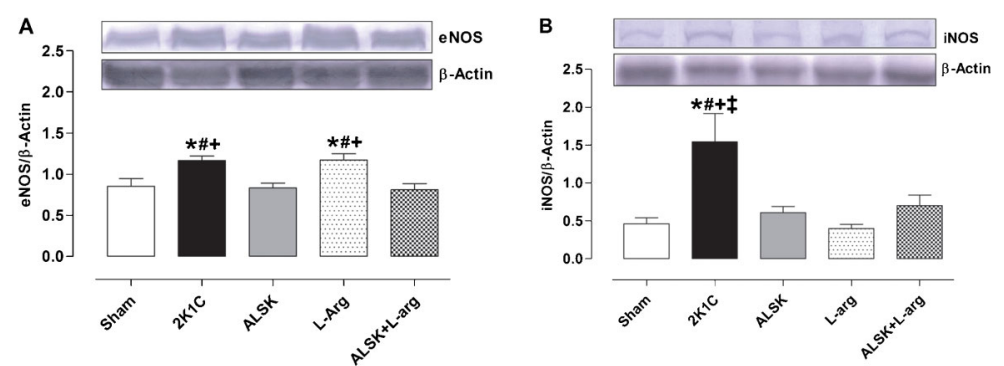

Figure 4. Effects of aliskiren (ALSK) and Larginine (L-arg) treatment in renovascular hypertension on the densitometric analyses of Western blotting for endothelial nitric oxide synthase (eNOS) $(A)$ and inducible nitric oxide synthase (iNOS) $(B)$. Data are reported as means $\pm \mathrm{SE}$. ${ }^{*} \mathrm{P}<0.05$ vs Sham; ${ }^{\#} \mathrm{P}<0.05$ vs ALSK; ${ }^{\dagger} \mathrm{P}<0.05$ vs L-arg; ${ }^{+} \mathrm{P}<0.05$ vs ALSK + L-arg (one-way ANOVA, followed by Fisher's post hoc test). 

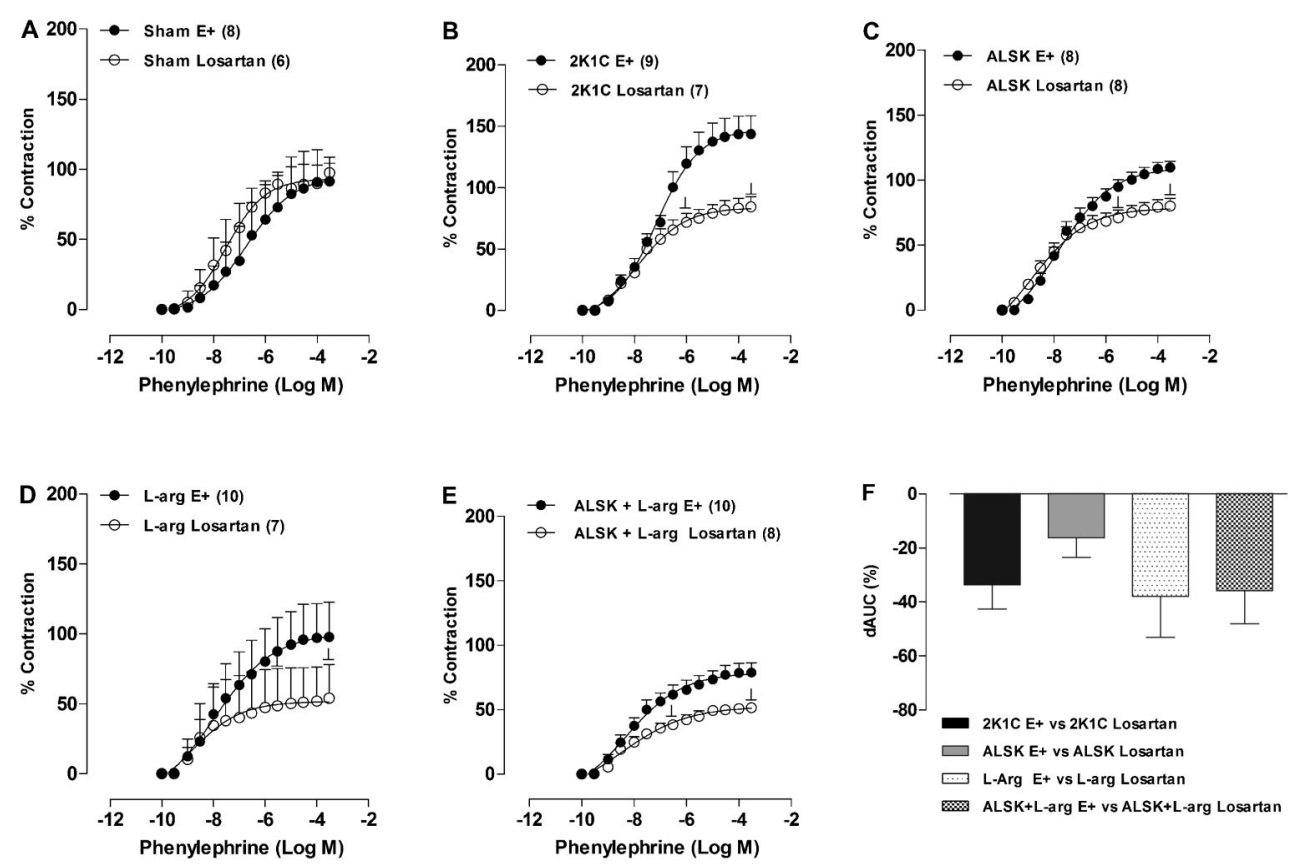

Figure 5. Effects of losartan $(10 \mathrm{mM})$ on the concentration-response curves to phenylephrine in endothelium-intact aortic segments from Sham $(A), 2 \mathrm{~K} 1 \mathrm{C}(B)$, aliskiren (ALSK) $(C)$, L-arginine (L-arg) $(D)$, and ALSK + L-arg $(E)$ treatments in aortic rings in the presence (losartan) and absence $(E+)$ of losartan blocker. The differences in the area under the concentration-response curves (dAUC) in the presence and absence of losartan are shown in $F$. The number of animals in each group is indicated in parentheses. ${ }^{\perp} \mathrm{P}<0.05 \mathrm{vs} E+$ (two-way ANOVA, followed by Tukey's post hoc test).

treatment in this response, $\mathrm{AT}_{1}$ receptors were blocked with losartan $(10 \mathrm{mM})$. As shown in Figure 5, losartan reduced the vasoconstrictor response induced by phenylephrine in aortas from the 2K1C (Figure 5B), ALSK (Figure 5C), L-arg (Figure 5D), and ALSK+L-arg (Figure $5 E)$ groups, but there were no differences in the dAUC values (Figure $5 F$ ). The $R_{\max }$ was decreased in the $2 \mathrm{~K} 1 \mathrm{C}$, ALSK, L-arg and ALSK + L-arg groups compared to the control $(E+)$, but not sensitivity to phenylephrine (Table 1). Additionally, $R_{\max }$ of $L$-arg and $A L S K+L$-arg were reduced compared to the $2 \mathrm{~K} 1 \mathrm{C}$ and Sham groups (Table 1). These findings suggested that $2 \mathrm{~K} 1 \mathrm{C}$ hypertension stimulated the local RAAS, and that only the combination of $A L S K+L$-arginine was able to correct this dysfunction.

To further investigate the involvement of the local RAAS on the effects of $2 \mathrm{~K} 1 \mathrm{C}$ hypertension and ALSK and $L$-arginine treatment, expression of the angiotensin $A T_{1}$ and $A T_{2}$ receptors was evaluated. Western blot analyses showed increased levels of $\mathrm{AT}_{1}$ receptor protein expression in the aortas from the $2 \mathrm{~K} 1 \mathrm{C}$ group compared with the Sham, ALSK and ALSK+L-arg groups (Figure 6A). AT 2 receptor protein expression was increased in the aortas from the ALSK +L-arg group compared with the Sham and L-arg groups (Figure 6B). Together, these results indicated that $2 \mathrm{~K} 1 \mathrm{C}$ hypertension induced endothelial dysfunction in conductance arteries through an upregulation of $A T_{1}$ receptor expression, and the ALSK and
L-arginine combination prevented these responses and also promoted an upregulation of $\mathrm{AT}_{2}$ receptor expression.

\section{Role of free radicals in the effects of ALSK and L-arginine treatment on the phenylephrine response}

To determine whether the endothelial changes observed in the aortic rings after $2 \mathrm{~K} 1 \mathrm{C}$ hypertension and ALSK and L-arginine treatment were related to changes in superoxide anion production, the effects of the superoxide anion scavenger SOD and the NADPH oxidase inhibitor, apocynin, on the vasoactive responses were analyzed. SOD reduced vascular reactivity to phenylephrine in the 2K1C (Figure 7B) and ALSK (Figure $7 C$ ) groups $(P<0.05)$. However, the magnitude of this response, as shown by the differences in the dAUC, was significantly greater in the $2 \mathrm{~K} 1 \mathrm{C}$ than in the ALSK group (2K1C: $-49.9 \pm 5.91 \%$ vs ALSK: $-29.6 \pm 6.93 \%, P<0.05$, Figure 7F). Additionally, SOD reduced the $R_{\max }$ of the $2 K 1 C$ and ALSK groups compared with the control $E+$ group and increased the sensitivity $\left(\mathrm{pD}_{2}\right)$ of $2 \mathrm{~K} 1 \mathrm{C}$ compared with control $\mathrm{E}+$. On the other hand, apocynin, an inhibitor of NADPH oxidase, reduced the phenylephrine responses in the aortic segments from group 2K1C (Figure 8B), ALSK (Figure $8 \mathrm{C}$ ), and $A L S K+L$-arg treated rats (Figure $8 \mathrm{E}$ ), but the decrease was smaller in the ALSK + L-arg group than in the $2 \mathrm{~K} 1 \mathrm{C}$ group; this difference was clearly seen when 

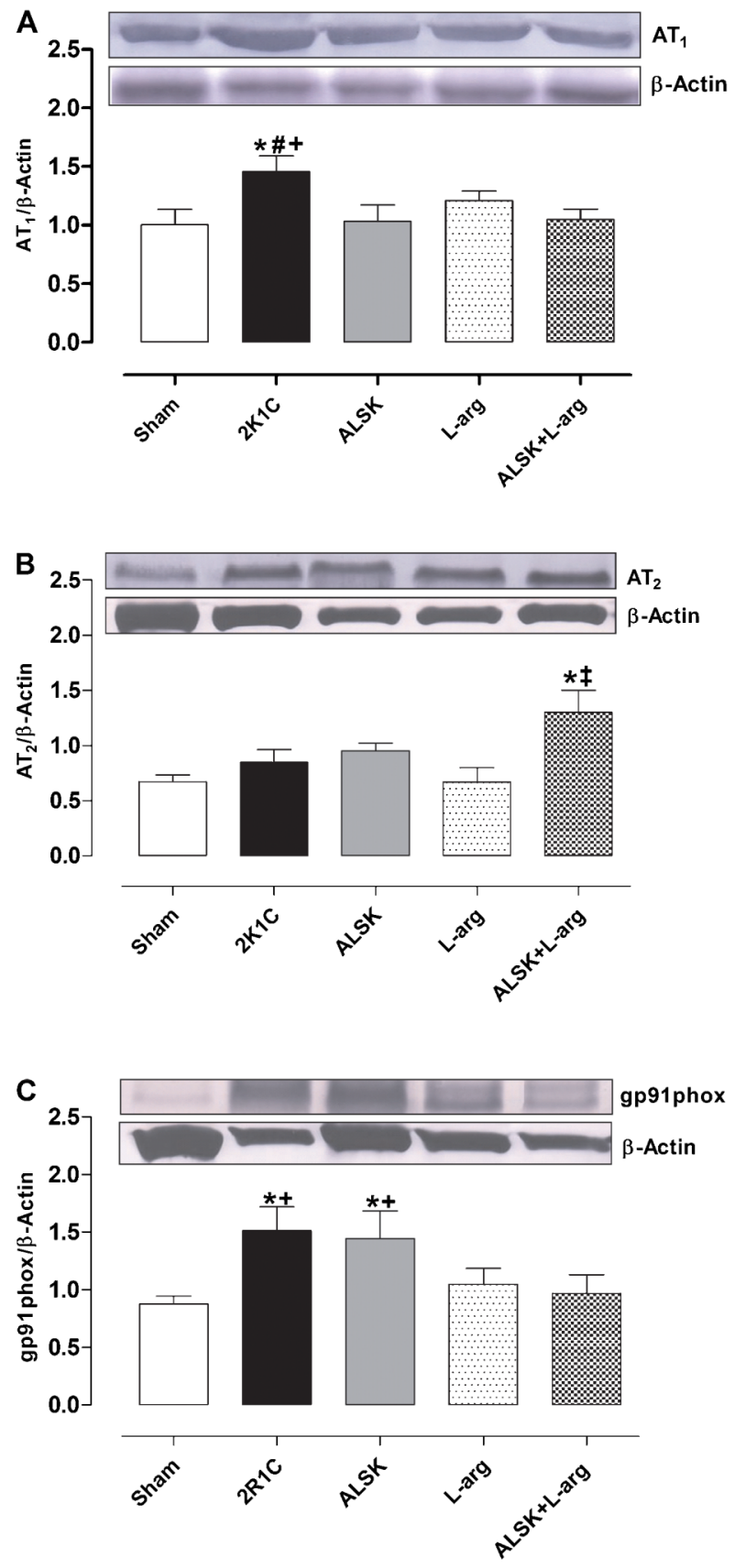

Figure 6. Densitometric analyses of angiotensin receptor-1 $\left(\mathrm{AT}_{1}\right)$ $(A), \mathrm{AT}_{2}(B)$ and gp91phox $(C)$ in aortas from Sham, $2 \mathrm{~K} 1 \mathrm{C}$, aliskiren (ALSK), L-arginine (L-arg), and ALSK +L-arg treated rats. Data are reported as means $\pm \mathrm{SE}$. ${ }^{*} \mathrm{P}<0.05$ vs Sham; ${ }^{\#} \mathrm{P}<0.05$ vs ALSK; ${ }^{*} \mathrm{P}<0.05$ vs L-arg; ${ }^{+} \mathrm{P}<0.05$ vs ALSK $+\mathrm{L}$-arg (one-way ANOVA, followed by Fisher's post hoc test).

dAUC were compared (2K1C: $-64.6 \pm 6.57 \%$ vs ALSK+L-arg: $-18.68 \pm 10.3 \%, P<0.05$, Figure $8 F)$. Incubation with apocynin reduced the $\mathrm{R}_{\max }$ of $2 \mathrm{~K} 1 \mathrm{C}$ and $\mathrm{ALSK}+\mathrm{L}$-arg groups compared with the Sham group.
$\mathrm{ALSK}+\mathrm{L}$-arg treatment also reduced $\mathrm{R}_{\max }$ compared with L-arg treatment (Table 1). To further investigate the involvement of the local oxidative stress on the effects of $2 \mathrm{~K} 1 \mathrm{C}$ hypertension and ALSK and L-arginine treatment, the expression of the gp91phox, the heme binding subunit of the superoxide-generating NADPH oxidase, was analyzed. Western blot analysis revealed increased levels of gp91phox-containing NADPH oxidase protein expression in the aortas from the $2 \mathrm{~K} 1 \mathrm{C}$ and ALSK groups compared with the Sham group. ALSK + L-arg treatment reduced the expression of this enzyme compared with expression in the $2 \mathrm{~K} 1 \mathrm{C}$ and ALSK groups (Figure $6 \mathrm{C}$ ).

\section{Discussion}

The present study demonstrated the effects of a 21-day treatment with ALSK and L-arginine, alone or in combination, on blood pressure and vascular reactivity to phenylephrine in rats with renovascular hypertension. The major findings of this study were as follows: $i$ ) the high levels of blood pressure promoted by the $2 \mathrm{~K} 1 \mathrm{C}$ model were partially restored by L-arg treatment, and were fully restored with the combination of L-arg and ALSK; ii) all treatments reduced the vasoconstrictor response to phenylephrine and prevented endothelial dysfunction; iii) the mechanisms related to the reduction in blood pressure and prevention of endothelial dysfunction in the ALSK + Larg group were most likely associated with improvements in the vascular RAAS and the reduction in oxidative stress. This is the first study to evaluate the effects of these treatments on vascular reactivity in this model of hypertension.

Renovascular hypertension is caused by an increased generation of angiotensin II owing to increased renal renin release. Therefore, excess angiotensin II production via several different effector pathways is at least partially responsible for the establishment and development of hypertension, left ventricular hypertrophy, and endothelial dysfunction $(6,7)$, which may result from the interplay of several mechanisms (20). We demonstrated that only the combination of ALSK and L-arg normalized blood pressure in rats with $2 \mathrm{~K} 1 \mathrm{C}$ hypertension, suggesting possible additive effects associated with combined therapy. ALSK induced negligible antihypertensive effects, but those effects were associated with a functional improvement in aorta reactivity to phenylephrine, suggesting that renin is a mediator in the pathogenesis of $2 \mathrm{~K} 1 \mathrm{C}$ hypertensiveinduced vascular alterations. Additional studies are needed to establish the mechanisms responsible for these responses. $2 \mathrm{~K} 1 \mathrm{C}$ hypertension increases vasoconstriction to phenylephrine in the aorta (2), which could be caused by a reduction in NO availability (5), or increased vascular superoxide anion production by activating vascular NADPH oxidase $(21,22)$.

To investigate endothelial modulation, the endothelium was removed. Following removal, we observed that 

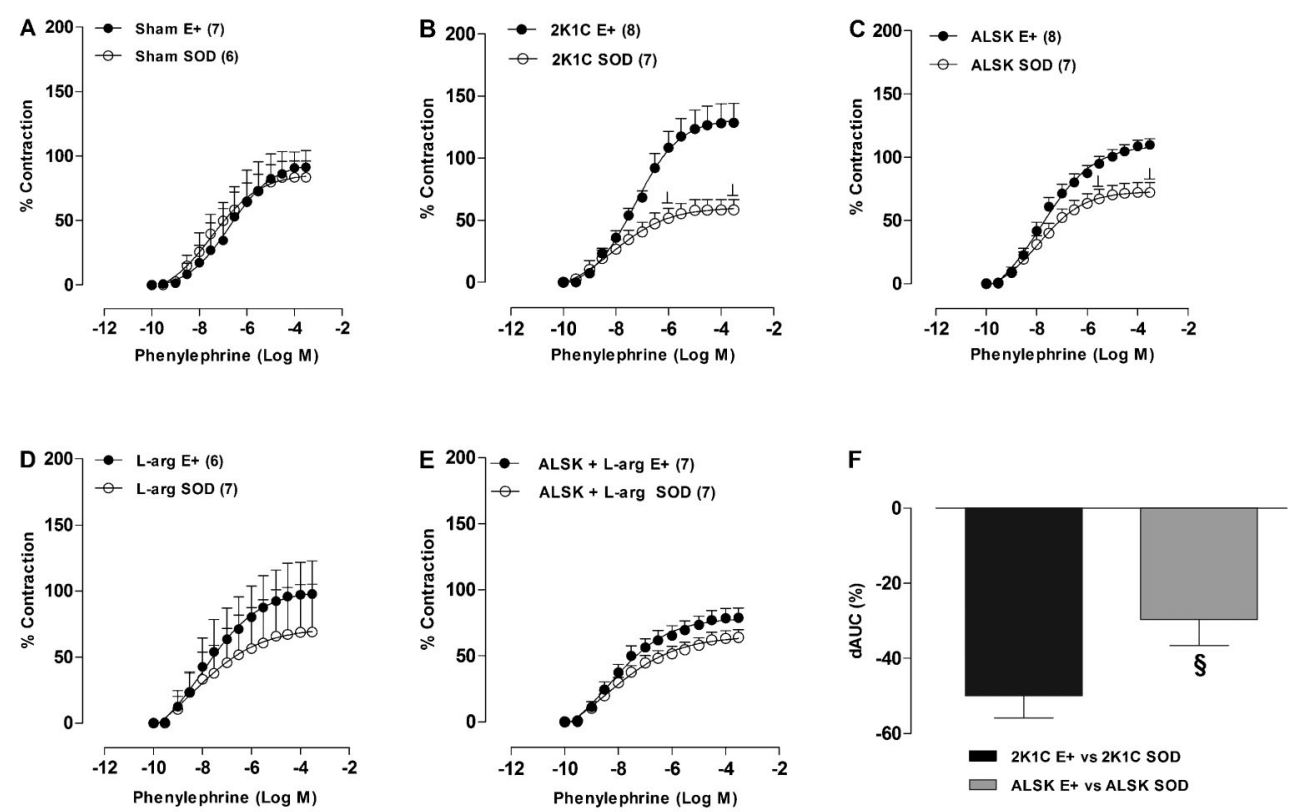

Figure 7. Effects of superoxide dismutase $(\mathrm{SOD}, 150 \mathrm{U} / \mathrm{mL})$ on the concentration-response curves to phenylephrine in endotheliumintact aortic segments from Sham $(A), 2 \mathrm{~K} 1 \mathrm{C}(B)$, aliskiren (ALSK) $(C)$, L-arginine (L-arg) $(D)$, and ALSK + L-arg $(E)$ treatments in aortic rings in the presence $(S O D)$ and absence $(E+)$ of SOD incubation. The differences in the area under the concentration-response curves (dAUC) in the presence and absence of SOD are shown in $F$. Data are reported as means \pm SE. The number of animals in each group is indicated in parentheses. ${ }^{\S} \mathrm{P}<0.05$ vs $2 \mathrm{~K} 1 \mathrm{C}$ and ${ }^{\perp} \mathrm{P}<0.05$ vs $\mathrm{E}+$ (two-way ANOVA, followed by Tukey's post hoc test).
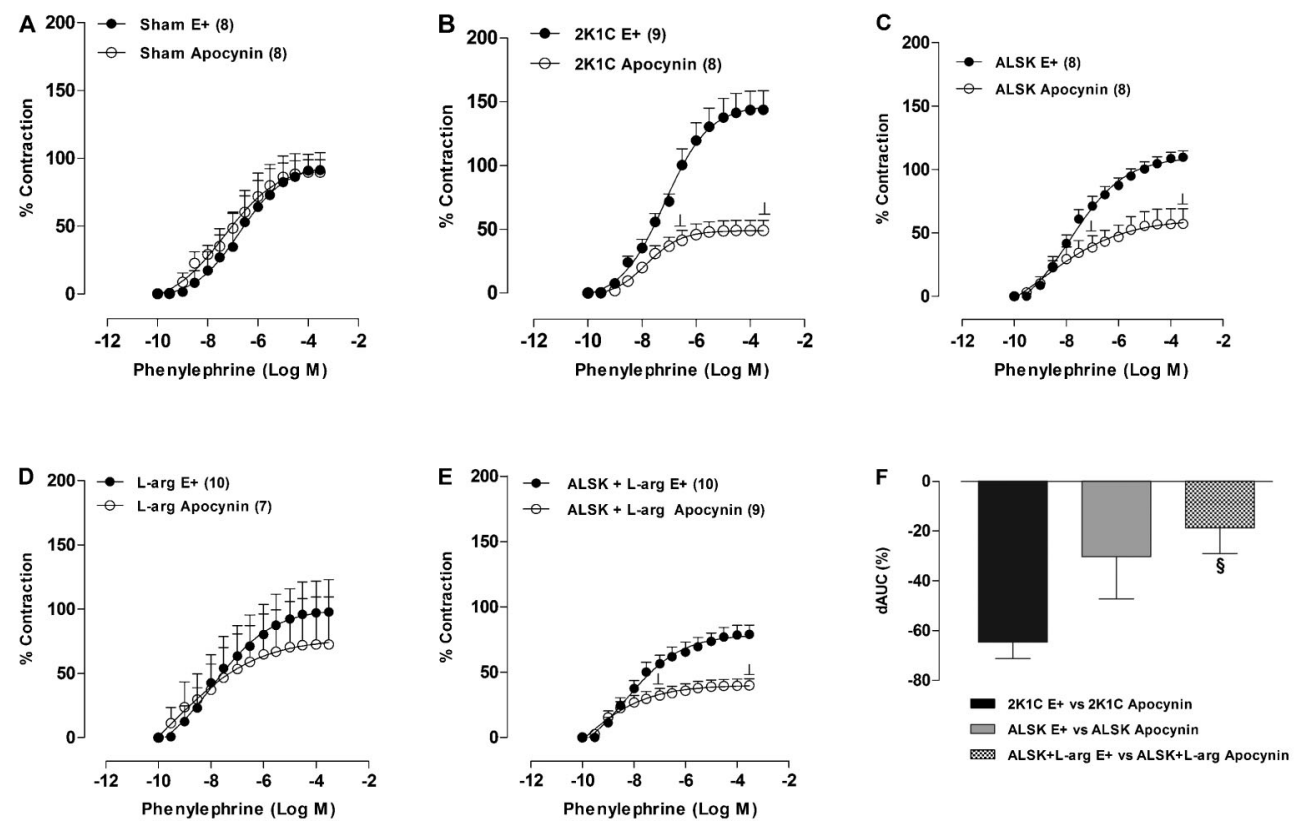

Figure 8. Effects of apocynin $(0.3 \mathrm{nM})$ on the concentration-response curves to phenylephrine in endothelium-intact aortic segments from Sham $(A), 2 \mathrm{~K} 1 \mathrm{C}(B)$, aliskiren (ALSK) $(C)$, L-arginine (L-arg) $(D)$, and ALSK + L-arg $(E)$ treatments in aortic rings in the presence (apocynin) and absence $(E+)$ of apocynin blocker. The differences in the area under the concentration-response curves (dAUC) in the presence and absence of apocynin are shown in $F$. Data are reported as means $\pm S E$. The number of animals in each group is indicated in parentheses. ${ }^{5} \mathrm{P}<0.05$ vs $2 \mathrm{~K} 1 \mathrm{C}$ and ${ }^{\perp} \mathrm{P}<0.05 \mathrm{vs} \mathrm{E}+$ (two-way ANOVA, followed by Tukey's post hoc test). 
the contractile response was enhanced in all groups; however, the magnitude of this response, as assessed by the dAUC, was higher in the rats treated with ALSK + Larg than in those given ALSK or $2 \mathrm{~K} 1 \mathrm{C}$ treatment alone. These data suggest that treatment with ALSK + L-arg was more effective in releasing an endothelium-derived relaxation factor. Other investigations have also indicated the involvement of the vascular endothelium in modulating renovascular hypertension $(5,23,24)$. Thus, the combination of drugs appeared to restore the endothelial dysfunction induced by the $2 \mathrm{~K} 1 \mathrm{C}$ model.

To investigate the role of $\mathrm{NO}$ in the $2 \mathrm{~K} 1 \mathrm{C}$ model and the treatment methods, NOS was inhibited by L-NAME. We observed that the contractile response was enhanced in all groups; however, the size of this response was higher in the groups treated with ALSK+L-arg and ALSK alone than in the $2 \mathrm{~K} 1 \mathrm{C}$ group. These data suggested that 2K1C hypertension induced endothelial dysfunction in conductance arteries, thereby reducing the endothelialinduced NO modulation of the vasoconstrictor response. Moreover, treatment with ALSK was crucial for endothelial modulation in the contractile response to phenylephrine. We also observed that $2 \mathrm{~K} 1 \mathrm{C}$ hypertension increased the expression of this eNOS isoform, corroborating the results of Hiyoshi et al. (25), who have also reported that $2 \mathrm{~K} 1 \mathrm{C}$ hypertension increases aortic levels of total eNOS. Other studies have demonstrated that mechanical forces on the vascular wall, such as blood pressure and shear stress, can increase the expression of eNOS in endothelial cells (26). Therefore, the increase in eNOS may be a compensatory mechanism of the reduced endothelial NO modulation observed in this hypertension model. However, despite the improvements in the vascular responses mediated by NO, eNOS protein expression in the groups treated with ALSK was not altered, in contrast to other reports that have shown an increased expression of this enzyme in double transgenic mice expressing human renin and angiotensinogen genes (27). The mechanism of NO-mediated vascular improvement with ALSK treatment might be related to an increase in eNOS activity, as reported in the SHR model (28), as well as to the $A T_{1}$ receptor restoration in our study, which reduced the activation of NADPH oxidase and ROS release and consequently augmented NO bioavailability.

$2 \mathrm{~K} 1 \mathrm{C}$ hypertension increased the expression of iNOS in the aortic rings of $2 \mathrm{~K} 1 \mathrm{C}$ rats. However, we also demonstrated that the iNOS was reduced by all treatments, suggesting that both drugs were effective in preventing the upregulation of iNOS observed in $2 \mathrm{~K} 1 \mathrm{C}$ rats. This finding is important because angiotensin II may induce an increased expression of iNOS in endothelial cells, and this effect is associated with increased oxidative stress and the generation of $\operatorname{ROS}(29,30)$. Moreover, previous studies have shown that the iNOS isoform is able to generate superoxide anions independent of $\mathrm{NO}$ production $(26,31)$.
Previous reports have shown that an increase in the concentration of angiotensin II increases the level of ROS in the aortas of normotensive and $2 \mathrm{~K} 1 \mathrm{C}$ hypertensive rats $(22,32)$ and that the superoxide anions, one of the most important radicals for vascular biology, can directly promote changes in vascular function and are also essential for the formation of other reactive species $(33,34)$.

Therefore, we investigated the involvement of the local renin-angiotensin system and the role of ROS on vascular reactivity to phenylephrine and the modulation of these systems by ALSK and L-arginine treatment. The losartanblocking effects suggest that $2 \mathrm{~K} 1 \mathrm{C}$ hypertension increased $A T_{1}$ receptor expression, which is in agreement with the upregulation of $A T_{1}$ receptor expression in the $2 \mathrm{~K} 1 \mathrm{C}$ group. These data suggest the involvement of the local renin-angiotensin system in this experimental model, which induces vasoconstriction and contributes to the increase in vascular reactivity. When the $A T_{1}$ receptor was inhibited with losartan (Table 1), the L-arginine and ALSK $+\mathrm{L}$-arginine treatments reduced $R_{\max }$ compared with the $2 \mathrm{~K} 1 \mathrm{C}$ and Sham groups, demonstrating the efficacy of these treatments in modulating the $A T_{1}$ receptor, as confirmed by the reduced $A T_{1}$ receptor expression in the ALSK+L-arg group. However, expression of the $\mathrm{AT}_{2}$ receptor was not different in the combined treatment group compared with the $2 \mathrm{~K} 1 \mathrm{C}$ group, suggesting that the enhanced vascular reactivity in the ALSK + Larg group was most likely not mediated by this receptor.

To better understand the role of oxidative stress in contractile vascular reactivity responses in $2 \mathrm{~K} 1 \mathrm{C}$ rats, an NADPH oxidase inhibitor (apocynin) and superoxide scavenger (SOD) were used. When the aortic rings were exposed to apocynin, the contractile response to phenylephrine was reduced in the $2 \mathrm{~K} 1 \mathrm{C}, \mathrm{ALSK}$, and ALSK+Larg groups; however, the magnitude of this response was lower in the ALSK + L-arg group compared with the $2 \mathrm{~K} 1 \mathrm{C}$ group, suggesting that ALSK $+\mathrm{L}$-arg is accompanied by reduced ROS production. Furthermore, treatment with L-arginine alone did not alter vascular reactivity to phenylephrine, suggesting that L-arginine could be the main factor involved in reducing ROS release. We also incubated aortic rings with SOD and obtained similar results to those with apocynin, demonstrating the efficacy of the treatments in reducing vascular oxidative stress. We also demonstrated that $2 \mathrm{~K} 1 \mathrm{C}$ hypertension increases gp91phox expression, suggesting that the increased vascular reactivity to phenylephrine induced by $2 \mathrm{~K} 1 \mathrm{C}$ hypertension might be caused by an increased release of ROS, most likely resulting in a reduction of NO bioavailability. Previous studies have shown that angiotensin II leads to the activation of NADPH oxidase in all vascular layers, a process that results in the scavenging of endothelium-derived $\mathrm{NO}$ and subsequent attenuation of endothelium-dependent relaxation (22). However, we have demonstrated that combined ALSK and L-arg 
treatment reduced the magnitude of contractile responses to phenylephrine and reduced gp91phox expression, suggesting that this combination treatment minimized the release of ROS. Jung et al. (22) demonstrated that the endothelial dysfunction observed during renovascular hypertension in mice results from the activation of endothelial gp91phox-containing NADPH oxidase, suggesting that combined ALSK and L-arg treatment could recover endothelial function.

The present study showed that combined ALSK+ $\mathrm{L}$-arg treatment was more effective in reducing blood pressure and preventing the endothelial dysfunction in

\section{References}

1. Frohlich ED. State of the Art lecture. Risk mechanisms in hypertensive heart disease. Hypertension 1999; 34: 782789, doi: 10.1161/01.HYP.34.4.782.

2. Yu TT, Guo K, Chen HC, Lan CZ, Wang J, Huang LL, et al. Effects of traditional Chinese medicine Xin-Ji-Er-Kang formula on $2 \mathrm{~K} 1 \mathrm{C}$ hypertensive rats: role of oxidative stress and endothelial dysfunction. BMC Complement Altern Med 2013; 13: 173, doi: 10.1186/1472-6882-13-173

3. Basile DP, Donohoe DL, Phillips SA, Frisbee JC. Enhanced skeletal muscle arteriolar reactivity to ANG II after recovery from ischemic acute renal failure. Am J Physiol Regul Integr Comp Physiol 2005; 289: R1770-R1776, doi: 10.1152/ ajpregu.00269.2005.

4. Min LJ, Mogi M, Li JM, Iwanami J, Iwai M, Horiuchi M. Aldosterone and angiotensin II synergistically induce mitogenic response in vascular smooth muscle cells. Circ Res 2005; 97: 434-442, doi: 10.1161/01.RES.0000180753.63183.95.

5. Higashi Y, Sasaki S, Nakagawa K, Matsuura H, Oshima T, Chayama K. Endothelial function and oxidative stress in renovascular hypertension. N Engl J Med 2002; 346: 19541962, doi: 10.1056/NEJMoa013591.

6. Garrido AM, Griendling KK. NADPH oxidases and angiotensin II receptor signaling. Mol Cell Endocrinol 2009; 302: 148-158, doi: 10.1016/j.mce.2008.11.003.

7. Versari D, Daghini E, Virdis A, Ghiadoni L, Taddei S. Endothelium-dependent contractions and endothelial dysfunction in human hypertension. Br J Pharmacol 2009; 157: 527-536, doi: 10.1111/j.1476-5381.2009.00240.x.

8. Toblli JE, DiGennaro F, Giani JF, Dominici FP. Nebivolol: impact on cardiac and endothelial function and clinical utility. Vasc Health Risk Manag 2012; 8: 151-160, doi: 10.2147/ VHRM.S20669.

9. Conlin PR, Gerth WC, Fox J, Roehm JB, Boccuzzi SJ. Fouryear persistence patterns among patients initiating therapy with the angiotensin II receptor antagonist losartan versus other artihypertensive drug classes. Clin Ther 2001; 23: 1999-2010, doi: 10.1016/S0149-2918(01)80152-1.

10. Savvatis K, Westermann D, Schultheiss HP, Tschope C. First-line treatment of hypertension: critical appraisal of potential role of aliskiren and hydrochlorothiazide in a fixed combination. Integr Blood Press Control 2010; 3: 163-170.

11. Duprez DA, Davis $P$, Botha J. The Ageless Study: The effect of aliskiren vs ramipril alone or in combination with hydrochlorothiazide and amlodipine in patients $=65$ years aortic rings of $2 \mathrm{~K} 1 \mathrm{C}$ hypertensive rats than the other experimental treatments. Moreover, the mechanisms responsible for these improvements appear to be related to the modulation of RAAS receptor expression, which is associated with the reduction in endothelial oxidative stress mediated by the NADPH oxidase system.

\section{Acknowledgments}

We are grateful to Paulo Henrique M. Silva for help on the experiments. Research supported by FAPES, CAPES, and CNPq. of age with systolic hypertension. Circulation 2008; 118: S886-S-887.

12. Stanton A, Jensen C, Nussberger J, O'Brien E. Blood pressure lowering in essential hypertension with an oral renin inhibitor, aliskiren. Hypertension 2003; 42: 1137-1143, doi: 10.1161/01.HYP.0000101688.17370.87.

13. Gradman $A H$, Schmieder RE, Lins RL, Nussberger J, Chiang Y, Bedigian MP. Aliskiren, a novel orally effective renin inhibitor, provides dose-dependent antihypertensive efficacy and placebo-like tolerability in hypertensive patients. Circulation 2005; 111: 1012-1018, doi: 10.1161/ 01.CIR.0000156466.02908.ED.

14. Schmieder RE, Philipp T, Guerediaga J, Gorostidi M, Smith $\mathrm{B}$, Weissbach $\mathrm{N}$, et al. Long-term antihypertensive efficacy and safety of the oral direct renin inhibitor aliskiren: a 12-month randomized, double-blind comparator trial with hydrochlorothiazide. Circulation 2009; 119: 417-425, doi: 10.1161/CIRCULATIONAHA.107.750745.

15. Gouvêa SA, Moysés MR, Bissoli NS, Pires JG, Cabral AM, Abreu GR. Oral administration of L-arginine decreases blood pressure and increases renal excretion of sodium and water in renovascular hypertensive rats. Braz J Med Biol Res 2003; 36: 943-949, doi: 10.1590/S0100-879X20030 00700017.

16. Jabecka A, Ast J, Bogdaski P, Drozdowski M, PawlakLemaska K, Cielewicz AR, et al. Oral L-arginine supplementation in patients with mild arterial hypertension and its effect on plasma level of asymmetric dimethylarginine, Lcitruline, L-arginine and antioxidant status. Eur Rev Med Pharmacol Sci 2012; 16: 1665-1674.

17. Gokce N. L-arginine and hypertension. J Nutr 2004; 134: 2807S-2811S.

18. Gouvea SA, Bissoli NS, Moysés MR, Cicilini MA, Pires JG, Abreu GR. Activity of angiotensin-converting enzyme after treatment with L-arginine in renovascular hypertension. Clin Exp Hypertens 2004; 26: 569-579, doi: 10.1081/CEH200031837.

19. Lowry $\mathrm{OH}$, Rosebrough NJ, Farr AL, Randall RJ. Protein measurement with the Folin phenol reagent. $J$ Biol Chem 1951; 193: 265-275.

20. Intengan HD, Schiffrin EL. Vascular remodeling in hypertension: roles of apoptosis, inflammation, and fibrosis. Hypertension 2001; 38: 581-587, doi: 10.1161/hy09t1. 096249. 
21. Ceron CS, Castro MM, Rizzi E, Montenegro MF, Fontana V, Salgado MC, et al. Spironolactone and hydrochlorothiazide exert antioxidant effects and reduce vascular matrix metalloproteinase-2 activity and expression in a model of renovascular hypertension. Br J Pharmacol 2010; 160: 7787, doi: 10.1111/j.1476-5381.2010.00678.x.

22. Jung O, Schreiber JG, Geiger H, Pedrazzini T, Busse R, Brandes RP. gp91phox-containing NADPH oxidase mediates endothelial dysfunction in renovascular hypertension. Circulation 2004; 109: 1795-1801, doi: 10.1161/01.CIR. 0000124223.00113.A4.

23. Rajagopalan S, Kurz S, Munzel T, Tarpey M, Freeman BA, Griendling KK, et al. Angiotensin II-mediated hypertension in the rat increases vascular superoxide production via membrane NADH/NADPH oxidase activation. Contribution to alterations of vasomotor tone. J Clin Invest 1996; 97: 1916-1923, doi: 10.1172/JCI118623.

24. Silva BR, Pernomian L, Grando MD, Amaral JH, TanusSantos JE, Bendhack LM. Hydrogen peroxide modulates phenylephrine-induced contractile response in renal hypertensive rat aorta. Eur J Pharmacol 2013; 721: 193-200, doi: 10.1016/j.ejphar.2013.09.036.

25. Hiyoshi H, Yayama K, Takano M, Okamoto H. Angiotensin type 2 receptor-mediated phosphorylation of eNOS in the aortas of mice with 2-kidney, 1-clip hypertension. Hypertension 2005; 45: 967-973, doi: 10.1161/01.HYP. 0000164571.77710 .19 .

26. Rochette L, Lorin J, Zeller M, Guilland JC, Lorgis L, Cottin Y, et al. Nitric oxide synthase inhibition and oxidative stress in cardiovascular diseases: possible therapeutic targets? Pharmacol Ther 2013; 140: 239-257, doi: 10.1016/ j.pharmthera.2013.07.004.

27. Savoia C, Arrabito E, Parente R, Sada L, Madaro L, Nicoletti $\mathrm{C}$, et al. The direct renin inhibitor aliskiren improves vascular remodelling in transgenic rats harbouring human renin and angiotensinogen genes. Clin Sci 2013; 125: 183-189, doi: $10.1042 / C S 20120395$.

28. Zhang W, Han Y, Meng G, Bai W, Xie L, Lu H, et al. Direct renin inhibition with aliskiren protects against myocardial ischemia/reperfusion injury by activating nitric oxide synthase signaling in spontaneously hypertensive rats. $J$ Am Heart Assoc 2014; 3: e000606, doi: 10.1161/JAHA 113.000606.

29. Sun J, Druhan LJ, Zweier JL. Reactive oxygen and nitrogen species regulate inducible nitric oxide synthase function shifting the balance of nitric oxide and superoxide production. Arch Biochem Biophys 2010; 494: 130-137, doi: 10.1016/j.abb.2009.11.019.

30. Alvarez $\mathrm{Y}$, Briones AM, Hernanz R, Perez-Giron JV, Alonso MJ, Salaices M. Role of NADPH oxidase and iNOS in vasoconstrictor responses of vessels from hypertensive and normotensive rats. Br J Pharmacol 2008; 153: 926-935, doi: 10.1038/sj.bjp.0707575.

31. Amaral LM, Pinheiro LC, Guimaraes DA, Palei AC, Sertorio JT, Portella RL, et al. Antihypertensive effects of inducible nitric oxide synthase inhibition in experimental pre-eclampsia. J Cell Mol Med 2013; 17: 1300-1307, doi: 10.1111/ jcmm.12106.

32. Griendling KK, Minieri CA, Ollerenshaw JD, Alexander RW. Angiotensin II stimulates NADH and NADPH oxidase activity in cultured vascular smooth muscle cells. Circ Res 1994; 74: 1141-1148, doi: 10.1161/01.RES.74.6.1141.

33. Taniyama Y, Griendling KK. Reactive oxygen species in the vasculature: molecular and cellular mechanisms. Hypertension 2003; 42: 1075-1081, doi: 10.1161/01.HYP 0000100443.09293.4F.

34. Touyz RM, Schiffrin EL. Reactive oxygen species in vascular biology: implications in hypertension. Histochem Cell Biol 2004; 122: 339-352, doi: 10.1007/s00418-0040696-7. 